\title{
Searching Life, the Universe and Everything? The Implementation of Summon at the University of Huddersfield
}

\section{Graham Stone}

\author{
Electronic Resources Manager/Repository Administrator, Computing \\ and Library Services, University of Huddersfield Queensgate, \\ Huddersfield HD1 3DH, UK, \\ g.stone@hud.ac.uk
}

'Why is Google so easy and the library so hard?' (Duddy, 2009)

\begin{abstract}
A review of the recent literature suggests that users prefer simple search interfaces such as Google. The implication here is that libraries often fail to make their resources discoverable and that this may in turn affect the perceived value of the library.

Against the background of the ongoing national debate about user expectations, a project group at the University of Huddersfield was asked to investigate the current provision for electronic resources and to look at a solution which would 'provide ease of searching and access for the user, whilst reducing the workload for systems and technical services and remaining within current budget levels'.
\end{abstract}

As a direct result of this review, the University of Huddersfield was the first UK commercial adopter of Summon in the summer of 2009. The Summon web-scale discovery service from Serials Solutions provides a simple single-search box to the breadth of the library's collection, swiftly delivering simultaneous information and results from the local catalogue and remote electronic resources offering a real alternative to the traditional federated search.

This paper will provide a case study of the implementation, evaluation and launch of this radical new service to users at the University of Huddersfield, by detailing the approaches used and lessons learned throughout the implementation period and making recommendations for future enhancements.

Key Words: Summon; resource discovery; metasearch; federated search 


\section{Introduction}

Problems with 'federated search' rank alongside lack of library textbooks as the perennial favourite in students' comments about the library (Stone, 2009 , p. 143). In order to tackle this issue, a review of electronic resources provision was undertaken by Computing and Library Services (CLS) at the University of Huddersfield in January 2009. The result of this review was the first UK commercial adoption of Summon from Serials Solutions. This was beta launched at the beginning of March 2010, to enable a period of user-testing alongside the existing federated search service, MetaLib, before a full launch in July 2010 and subsequent roll-out for the academic year 2010/11.

The key aims of this paper are:

- To describe the rationale behind the e-resources review and the subsequent decision to move away from federated search.

- To report on the objectives for implementation, challenges encountered and any issues raised during the technical implementation of Summon, including MARC mapping from the library catalogues, population of full text resources via Serials Solutions and the University Repository and inclusion of locally held collections.

- To discuss the feedback received from a representative sample of users after the initial beta launch of the service in order to refine and approve the system for a full launch in July 2010.

- The very nature of Summon will completely change the way user education is approached at Huddersfield. The paper will go on to consider some of the changes that will be made to the information literacy strategy as a result of the adoption of Summon.

- Finally, the paper will discuss any future enhancements that may be necessary to improve the system and to share lessons learned from the project.

\section{Literature Review}

Recent Research Information Network (RIN) reports (RIN 2008, 2009) have discussed how researchers look for content and whether or not it is easy for them to discover this content through the library and other providers. This 
research shows that there are a number of different starting points for research and that the complexity of starting points and the difficulties in finding available data in different silos of information are key issues for both researchers and libraries (RIN, 2009, p. 24). This complexity may lead researchers to turn away from the library altogether.

Nicholas et al. (Nicholas, 2009, p. 128) found that undergraduates and postgraduates were the ones most likely to use library electronic resources, suggesting a 'hot link' role for libraries. However, are libraries failing to make their resources discoverable? Librarians spend a large amount of their time teaching users how to search a variety of different interfaces. At the 2009 UKSG Conference Dave Pattern asked: 'Why do we want to teach our users to be librarians?' (Pattern, 2009) A student speaker wondered, 'Why is Google so easy and the library so hard?' (Duddy, 2009).

Questions like these and the threat of Google convinced many libraries to move to federated search in the last ten years. This is now a mature market with many products having come and gone from the marketplace. However, 'The jury is still out on federated search systems, even though more libraries now have them. There are murmurings that federated search has lowerthan-expected use and may not be the magic search bullet we were led to believe' (Tenopir, 2007, p. 30). King (King, 2008) observes that many librarians do not recommend federated search, despite actual usage increasing. Research at Stockholm University shows that students were not enthusiastic about Google Scholar or MetaLib; but they agreed that Google Scholar was easy to use (Nygren, 2006). Lampert and Dabbour conclude that students regard federated searching as 'just another tool' (Lampert and Dabbour, 2007, p. 271).

Although no tool for uncovering academic information is entirely comprehensive in its coverage, not even Google Scholar, a range of new generation resource discovery systems have emerged (Mayfield, 2008; Stevenson, 2009; Blenkle, 2009). These tools '...harvest all of the relevant sources of data, normalize them into a single metadata schema, and index all of them together in one large union index. This approach offers huge advantages in speed and in the logic that can be applied to the presentation and sorting of results' (Gibson, 2009, p. 126). Lauridsen and Stone conclude that the key for the medium term is to provide Google-like interfaces with Google-like results (Lauridsen and Stone, 2009). Breeding agrees that although resource 
discovery tops the charts of library automation issues, 'We are also still in very early days of these new web-scale discovery platforms. While the concepts seem quite attractive, it will only be through the experience of the library users that these products will either prove themselves or not' (Breeding, 2010, 34).

Bell warned that we will have failed if our efforts to triumph over Google and search engines are at the expense of information literacy (Bell, 2005). Nicholas states that the move towards a fully digital library will see a change in user behaviour that brings about the real possibility that librarians and libraries will become removed from their users (Nicholas, 2008, p. 1). Walker considers this change as an opportunity to collect user information and to monitor use, and likens it to a goldmine (Walker, 2009, p. 182). Whatever the views, we cannot assume that we know best for the user (CIBER, 2007); as Shipp succinctly puts it, 'We're facing challenging budget years ahead. It's essential that we raise the profile of the library and demonstrate real value' (Shipp, 2009).

\section{Review of Electronic Resources Provision}

In January 2009, CLS established an electronic resources provision working group to review the present solution, which had been in place since 2006. This working group was chaired by a senior member of Computing Services and consisted of key members of library staff from subject teams and technical services.

The aim of the working group was to evaluate the marketplace and to ascertain whether there were any systems that could '...provide ease of searching and access for the user, whilst reducing the workload for systems and technical services, and remaining within budget levels'. At this point in time, the working group had fairly broad objectives such as outlining what was needed, and evaluating products ranging from those supplied subscription agents, library systems vendors, publishers and other commercial companies and open source solutions. The working party was charged with reporting back to the Library Management Group by May 2009 to 'make recommendations for further provision, e.g. for the next 5 years, taking into account system interoperability and future-proofing'. 


\section{The Vision}

Before investigating the marketplace, the working party took a 'clean sheet of paper' approach and identified four main 'vision objectives' for a future system

- A first class search engine: this was seen as the most critical objective. The solution needed to be capable of returning relevant, accurate results and provide a Google-like experience for users.

- The 'one-stop-shop': a single interface was required for users to be able to access all library resources, e.g. library catalogue, full text journals, e-books, the Repository and other university systems, via a single search.

- Improved value for money: any solution needed to provide better value for money for purchase and ongoing maintenance costs while also significantly reducing administration costs for library staff.

- Improved system management: the solution needed to provide 'back-end' system management by being interoperable and running on open standards.

\section{Supplier Evaluation}

The working party vision was then expanded into an evaluation document, which was used to assess the strength of each product. A number of suppliers were invited to give 45-minute demonstrations and afterwards the working party rated the products against the vision.

In May 2009 a report was tabled at the Library Management Group, which resulted in a tender to the Official Journal of the European Union (OJEU) in June of that year. In late August 2009, the contract was awarded to Serials Solutions and the University of Huddersfield became the first UK commercial adoption of Summon (Serials Solutions, 2009).

\section{Implementation}

The initial stage of the implementation was to agree timescales with stakeholders in the library and Serials Solutions. Table 1 shows the original 
implementation plan and the actual dates of implementation. It also shows clearly that the estimation and actual date of a number of milestones were altered as the project progressed. The reasons behind these changes are outlined below. It is important to note that the library was also moving subscription agents from EBSCO, including EBSCO A-Z, to Swets and Swetswise at the same time as the project and that this had a direct impact on some of the timescales.

Table 1: Implementation timescales

\begin{tabular}{lll}
\hline Milestones & $\begin{array}{l}\text { Estimated implementation } \\
\text { Date }\end{array}$ & $\begin{array}{l}\text { Actual implementation } \\
\text { Date }\end{array}$ \\
\hline Contract signed & Aug 2009 & Aug 2009 \\
Implementation starts & Sep 2009 & Sep 2009 \\
Summon instance delivered & Oct 2009 & Oct 2009 \\
Beta launch & Jan 2010 & Mar 2010 \\
360 Link to replace SFX & Aug 2010 & Feb 2010 \\
E-resources wiki to go live & Aug 2010 & Mar 2010 \\
Summon to replace MetaLib & Aug 2010 & Aug 2010 \\
\hline
\end{tabular}

The implementation itself kicked off with a conference call between Technical Services staff, including Dave Pattern (Library Systems Manager), who was responsible for all in-house customisation and Serials Solutions staff in the United States followed by training in the various 360 modules. The initial customisation of Summon was configured, e.g. branding and the completion of the MARC21 mapping spreadsheet.

\section{Marc Records}

Before the MARC21 mapping spreadsheet could be completed, it was decided that in order for Summon to correctly identify books and e-books and print and e-journals, the MARC records would need to be separated. Print journals with an 856 field relating to a link to EBSCO A-Z had this field deleted, as this service was to be discontinued at the end of 2009. Monograph records that had previously been merged as part of the acquisitions process were split and then globally edited in order to create separate print and e-book records before loading into Summon. 
The default settings were used on the MARC21 mapping spreadsheet, which was then returned to Serials Solutions. All print books and journal records were then exported into Summon. In-house scripts were then developed to upload deletions, changed records and new records on a daily basis. As to be expected, this process did not run as smoothly as planned. There were initial communication issues with deletions, which took some time to be processed, although this is now working well with updates from the catalogue to Summon running four times a day. At this point it was decided not to include e-books, e-journals, fast adds, temporary Inter Library Loan records and records that were on order or unavailable in the upload.

Another major issue that the MARC21 upload revealed was that there were some major inconsistencies in cataloguing practices over the years. This was especially evident for music scores, which after the initial upload failed to show in Summon. In addition, many DVDs showed as books. These errors were quickly highlighted as an issue with 'copy cataloguing' where the same error had been duplicated many times. Global edits rectified this situation when it was found that the errors were in the MARC header fields. However, these issues were of enough concern for the Implementation Group to put back the planned beta launch from January to March 2010.

\section{Core}

Summon uses the 360 Core knowledge base to populate subscribed resources. The original plan was to use this to link to the SFX link resolver until switching to 360 Link in July 2010. The aim of this approach was to minimise disruption during the academic year and to give the journals team the opportunity to first move the subscriptions from EBSCO to Swets and then move link resolvers. However, the subscription agent change and migration of data from SFX to 360 Link went so smoothly that the majority of changes were completed by Christmas 2009. The Summon Implementation Group was shown 360 Link in January 2010 and the overwhelming response was to move to 360 Link as soon as possible. This was partly due to the interface, but also to the increase from 22,000 titles in SFX to over 50,000 in 360 Link.

Since the switch there have been a number of customisations to the standard 360 interface. Figure 1 shows the addition of an RSS feed next to the journal title using ticTOCs. A Summon search box has also been introduced which 
enables users to search for article level content within the journal title at this stage. Print holdings and aggregated content are always displayed at the bottom of the list of links. Finally, a basic in-house recommender service, based on historical MetaLib/SFX data, is also available to users. It is hoped to use Summon data in future.

Fig. 1: Customised version of 360 Linker page.

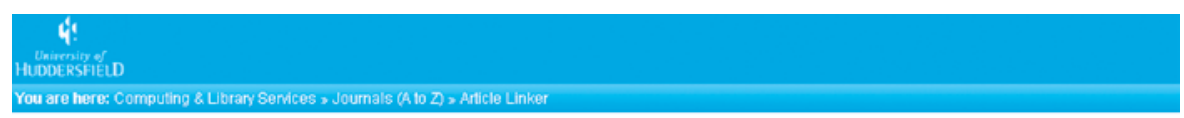

\section{Details:}

Journal: British joumal of criminology

ISSN: 0007-0955

Content is available via the following links

\begin{tabular}{|c|c|c|}
\hline Coverage Range & Click here for full text & Resource \\
\hline $1960 \cdot 1995$ & Journal & online: Oxford Joumals Archive - JISC (Sublicense A) \\
\hline 1996 - present & Journal & online: Oxford Journals Law Collection \\
\hline 1996 - present & Journal & online: Oxford Joumals Social Sciences Collection \\
\hline 2003 - present & Journal & online: Swetswise Online Content \\
\hline \multirow[t]{2}{*}{$1972 \cdot 2010$} & Journal & print joumal held in the Library \\
\hline & Journal & online: Westlaw UK \\
\hline
\end{tabular}

Search within this journal (beta)

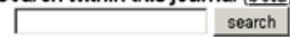

Need Help?

- report a problem

People who looked at this journal, also looked at...

- Criminology and criminal iustice an intemational journal (ISSN 1748-8958)

- Criminology (Beverly Hills) (SSN O011-1384)

- Theoretical criminology (ISSN 1362-4806)

- Howard joumal of criminal justice (ISSN 0265-5527)

- Critical criminology (Richmond. B.C) (ISSN 1205-8629)

- Crime law and secial change (ISSN 0925-4994)

- Crime and delinquency (ISSN 0011-1287)

- open criminology joumal (ISSN 1874.9178)

- ieumal of forensic psychiatry \& esychology (ISSN 1478-9949)

- Burnal of forensic psychiatry \& esychology (ISSN

\section{Other Library Resources}

The University Repository includes journal articles, book chapters, working papers and reports and non-textual material such as art. The loading of data to Summon was relatively seamless, although there has been an ongoing issue regarding Repository items that do not contain full text appearing in a Summon search of library content. Repository data is also available to other Summon customers, providing they link via 360 Core. Other repositories are also available to Huddersfield and are currently being enabled. 
Digital off-air recordings replaced the traditional video/DVD off-air recordings as part of the Educational Recordings Agency (ERA) licence in the library collection some 18 months ago. These items are now fully searchable within Summon, although not available to other Summon customers, and are password protected. It is hoped to add streaming videos of lectures in the near future.

\section{Lessons Learned}

Throughout the implementation of Summon, there were a number of concerns expressed by members of the group, while other issues were reported by Summon customers around the world. Many of these concerns have been addressed above, the remainder are detailed below.

Journal records. It had been reported that users in other universities had tried to find journal titles within Summon. However, if a journal title is searched, although all articles are retrieved, a link to the journal itself is not available. Two approaches were used to prevent this; firstly, the default Summon front page was customised. The Huddersfield instance of the Summon front page is shown in Figure 2. This provides a link to the A-Z list of journals via 360, e.g. Figure 1. This list of journals was then used to create dummy MARC records in the library catalogue. These records were then loaded into Summon. Therefore, when a search for a journal title is performed in Summon, these dummy records will display at the top of the search results providing a direct link to the journal homepage via 360 Link (see Figure 3).

E-resources. Federated searching was extremely unpopular at Huddersfield. As a result the majority of searches in MetaLib were done by browsing the subject lists and then selecting an appropriate database to search. This approach was not supported by Summon. However, it was expected that a significant number of academic staff would still recommend this approach to students, thereby creating negative feedback if only the default Summon page was used.

An electronic wiki was already in use to provide access to help guides etc. This was due to be rebranded in the summer, however, this was brought forward to March (Figure 4). A link was then placed on the customised Summon front page (Figure 2). Dummy MARC records were also produced 
Fig. 2: University of Huddersfield Summon front page.

4. University of HUDDERSFIELD

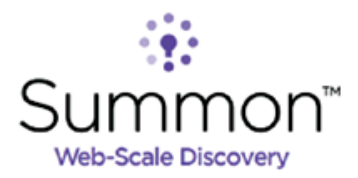

Easily discover the world of library content

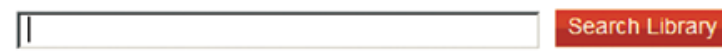

Advanced Search

Take Summon for a test drive today and please give us your comments! complete the Summon Survey for a chance to win $£ 10$ printing/photocopying credit

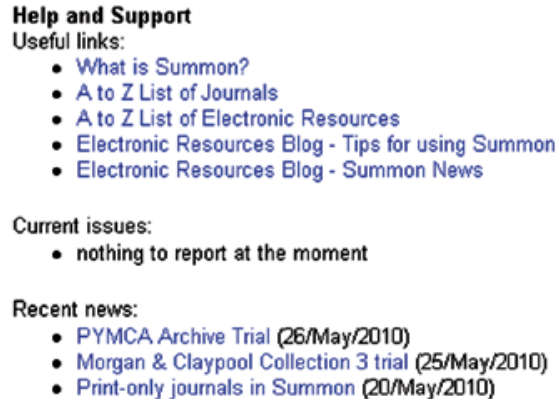

for databases to enable users to search for a database within Summon. At the same time Serials Solutions launched their recommendation service, which uses keywords and data in the knowledge base to point users to other electronic resources (Figure 5).

Implementation time. Although the actual implementation of Summon was completed within the six-week timeframe, the project was a little ambitious in hoping to have everything ready for the beta launch in January 2010, due partly to the customisations described above. However, the project had 
Graham Stone

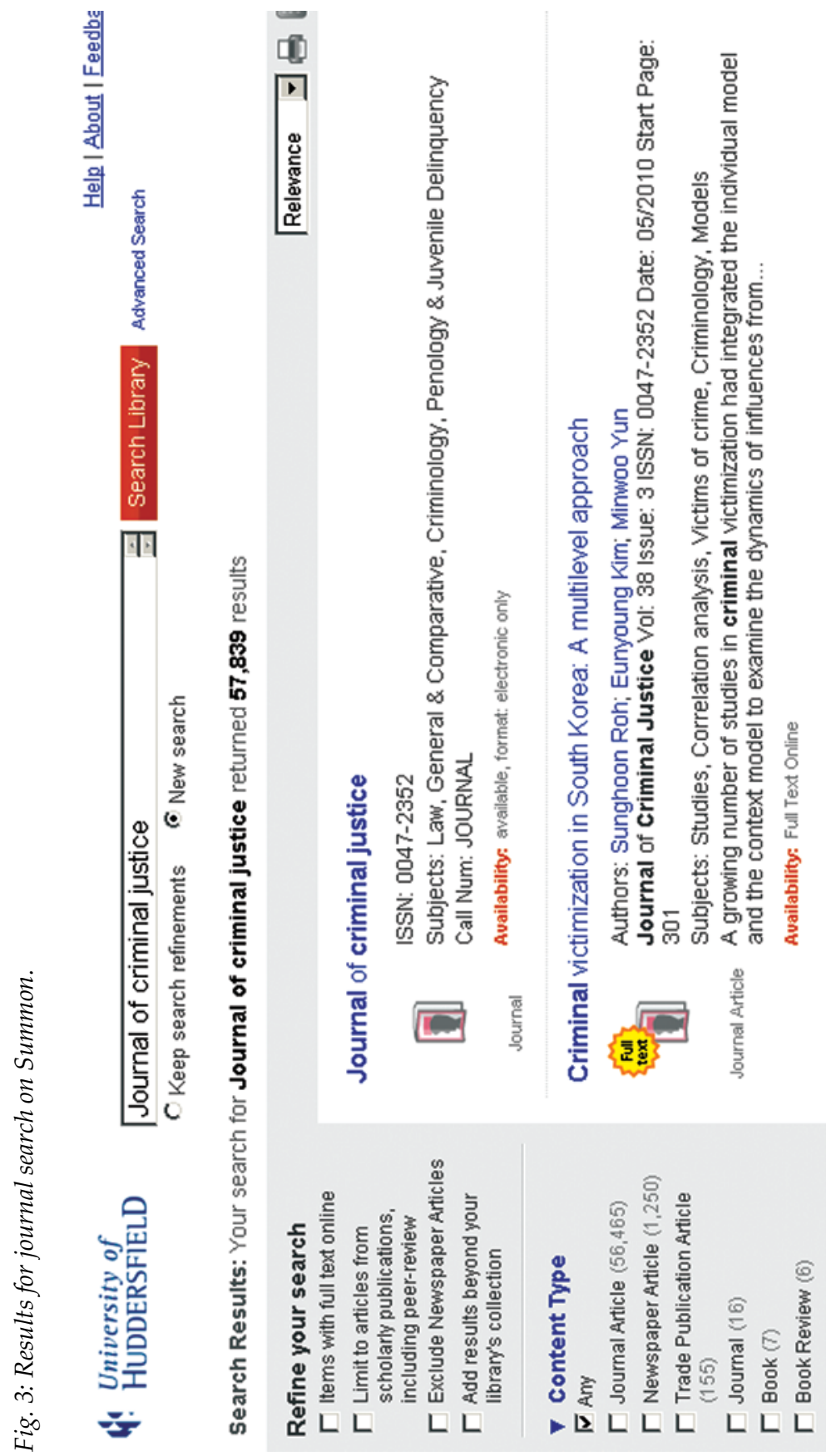




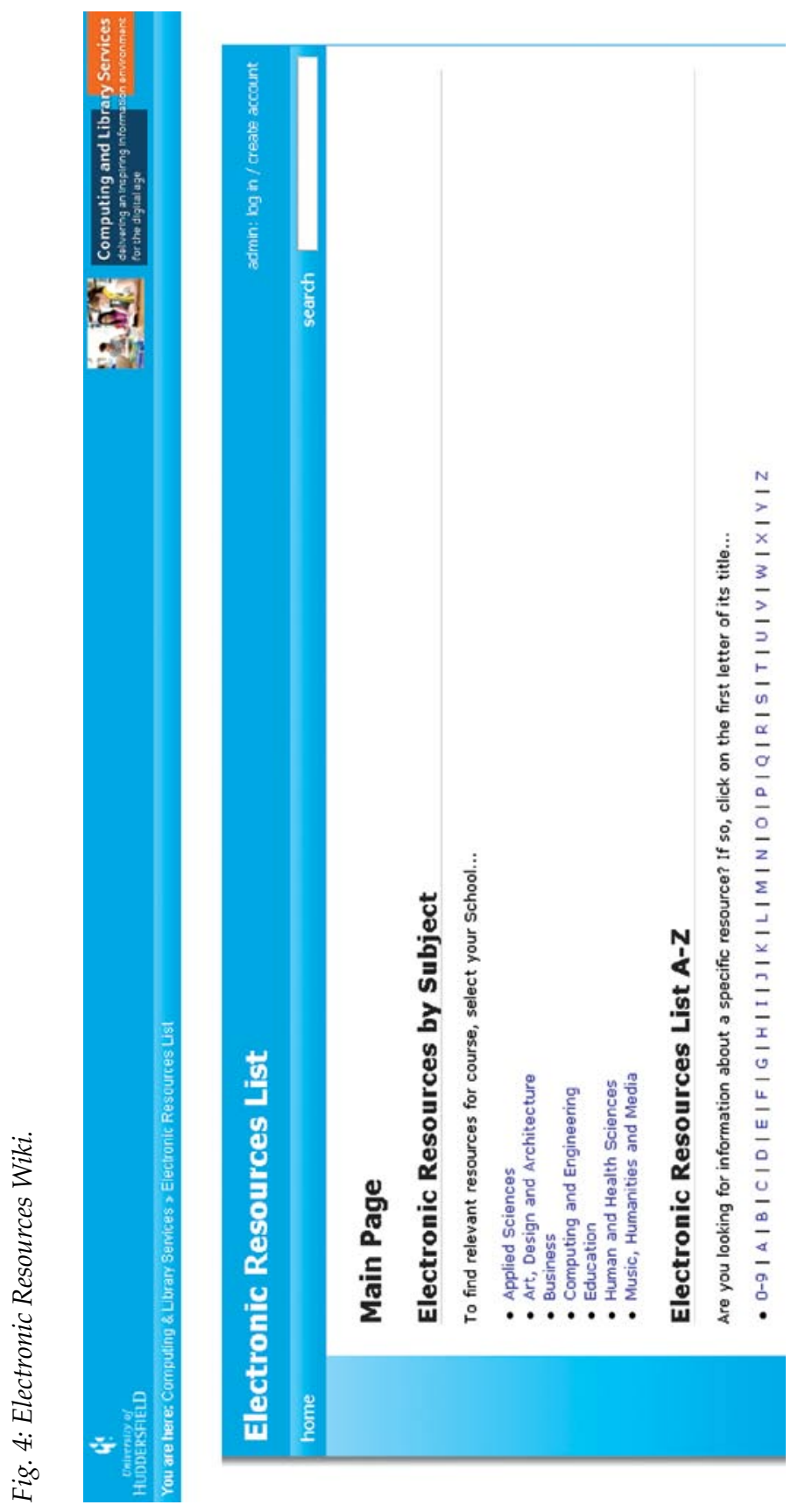


Graham Stone

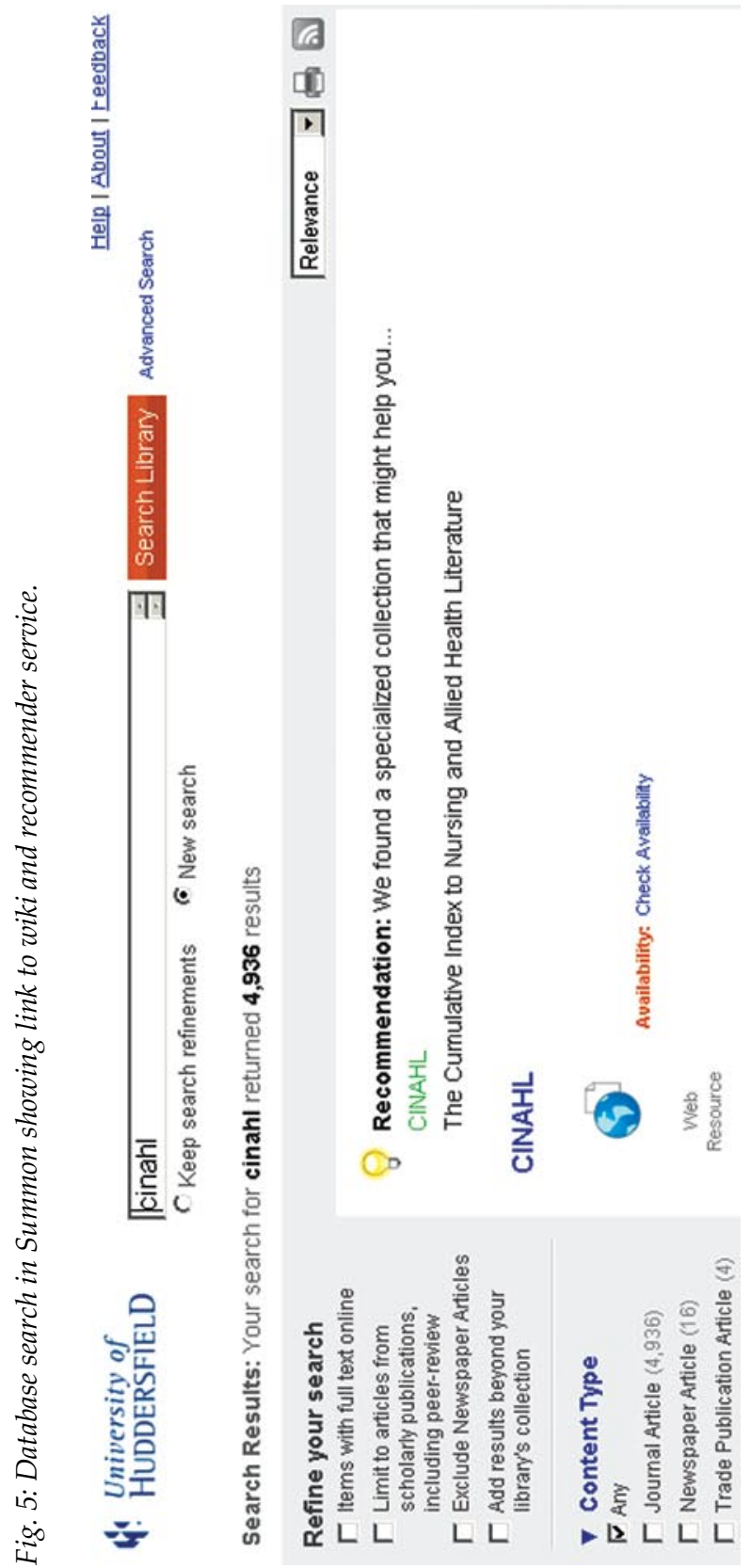


significant recovery time to enable a full launch in July 2010 to go ahead. This may have proved a major issue had the project not planned such a long lead in time.

\section{Beta Launch}

MetaLib was launched in 2006 with a big bang approach and received its fair share of criticism because of this. From the outset, the Summon Implementation Group felt that this was not the right approach for Summon. Even though MetaLib was widely criticised by library staff and students alike, those resistant to change may have disliked Summon purely on the basis that it was a change that had been enforced upon them.

Therefore the soft launch in January 2010 was planned with a period of dual running alongside MetaLib, with the latter phased out at the end of July 2010. This beta period gave the library service time to introduce the new service and users time to react. The slip of the beta launch from January to March was not seen as significant, leaving nearly five months of user testing. Indeed the group preferred a March launch of a more developed service which included $94 \%$ of journal within SFX, an additional 30,000 titles and all of the resources detailed above. As such, Summon was successfully beta launched on 10 March at the University Research Festival.

\section{Marketing Strategy}

As part of the build-up to the launch of Summon in July 2010 and the subsequent roll-out in the 2010/11 academic year, the Summon Implementation Group compiled a marketing review for Summon and associated library electronic resources. This is a requirement of all projects within CLS. The review was agreed after comment by the CLS Marketing and Communications Strategy Group.

The objective of the review was to determine the needs, wants and interests of users and to use an evidence-based approach to deliver the desired satisfactions effectively and efficiently. As part of this process, the benefit to potential users was defined in addition to details of the customer groups that would be targeted and related groups that needed to know about the service. This 
customer segmentation was then used to define different work packages within a separate marketing plan.

Benchmarking against other services implementing Summon was also used to learn from other positive and negative experiences.

The marketing plan covers the period from March to September 2010 and comprises five work packages (Table 2). A new marketing review document and plan will be ready for September 2010 to cover the first full year of the service.

Table 2: Marketing Plan work packages

\begin{tabular}{ll}
\hline Work Package & Objective \\
\hline Interface & $\begin{array}{l}\text { To promote Summon front page and make necessary interface } \\
\text { changes } \\
\text { Publicity }\end{array}$ \\
Evaluation and Feedback & Ensure Summon is fit for purpose by launch \\
CLS Staff training & To ensure full training across service \\
User training & To ensure relevant stakeholders are offered training \\
\hline
\end{tabular}

The interface work package has been discussed above; the other four work packages are discussed in detail below. At this time, the University of Huddersfield and Northumbria were also successful in the application for a JISC call, Enhancing library management systems, the project blog will detail the outcomes of this project which is due to report in October 2010.

\section{Publicity}

Despite Serials Solutions regarding Summon as being intuitive to first-time users, it was felt that a significant amount of time needed to be invested in creating introductory guides and leaflets.

The Implementation Group felt that a successful publicity campaign and subsequent user evaluation and training were key factors in the transition between MetaLib and Summon. A variety of approaches were adopted. Firstly there were a number of press releases via the staff bulletin (a weekly email), the staff newsletter, Huddle, and the student newsletter. A number of early adopters from the beta launch were asked for comment; one such comment 
from a senior researcher, 'Summon is bloody brilliant', was used in the student newsletter and became the catchphrase for the whole Implementation Team. In addition, positive comments were drip-fed via the Library Twitter account and the E-resources Blog, which now feeds items with a separate Summon tag to the Huddersfield Summon page.

Other publicity, such as adding a Summon link to the staff and student portal pages and Blackboard, the University's virtual learning environment (VLE), were ready for the beta launch in March. In a more ambitious move, the Implementation Group has discussed having large banners placed in the entrance to the library by September (Duvernay, 2010) and projecting a rolling PowerPoint slideshow onto the side of the Creative Arts Building, situated opposite the library entrance. Finally a number of online guides have been created using screen capture software; the demo version is available at http://eprints.hud.ac.uk/7509/.

More traditionally, a number of flyers, leaflets and guides were produced inhouse to advertise the new service and the availability of drop-in training sessions. It was decided to solicit user feedback regarding these leaflets during the beta test in order to ensure that the right message was being conveyed and to contribute to the substantial re-write of the various undergraduate and postgraduate handbooks, guides and web pages that mentioned electronic access to resources.

The original Summon flyer used around the time of the beta launch was an attempt to allay fears from academics and researchers about the change in service. This flyer explained Summon as a concept, the reasons behind the replacement of the current service and the potential impact on teaching, learning and research by giving advanced warning that course materials would need to be updated by September.

Perhaps the most successful leaflet was the 'Using Summon is as easy as 1-2-3 ...' guide. This A5 gatefold leaflet introduced the user to the Summon front page and the search results page:

1. Enter search term(s) into the search box

2. Refine the results by choices such as date, subject, academic journals and other options

3. View results and click to follow link to full text 
This approach was adopted after informal comments from other universities suggested that the use of facets on the left hand side of the results screen was not as high as expected. Evidence from user evaluation (see below) seems to suggest that this leaflet was successful in encouraging users to use this feature.

User guides and flyers continue to be updated as new functionality is added to Summon, a sample of these can be found on the ISC project blog.

\section{User Evaluation}

In the period between the beta launch in March and the full launch in July it was decided to undertake user evaluation in order to ascertain whether technical implementation had been successful from a user perspective. User evaluation began with direct feedback from those who attended the launch; more co-ordinated feedback was collated using a feedback questionnaire and focus groups. Other user comments were obtained via subject teams, the e-resources blog, student panels, course committees, and anecdotal feedback through user training.

\section{Questionnaire Results}

To coincide with the beta launch, a link to a user questionnaire was provided from the front page of Summon. The questionnaire was designed, using Bristol Online Surveys, to be quick to complete comprising twelve questions. A monthly prize of free print quota was used to encourage users to participate. In addition, users were asked to provide their contact details if they would be happy to be approached to take part in more detailed focus groups, $35 \%$ of the 91 respondents indicated they would be interested.

Figures 6 and 7 shows the types of respondents and their school represented in the survey. $90 \%$ reported that the Summon screens were easy to understand and $88 \%$ found the icons easy to use. The majority of those who left a comment felt that they would not require any help in using Summon. This result was encouraging, given that a simple, intuitive search interface was integral to the decision to purchase Summon. One notable comment was that 
Fig. 6: Percentage distribution of online surveys respondant replies.

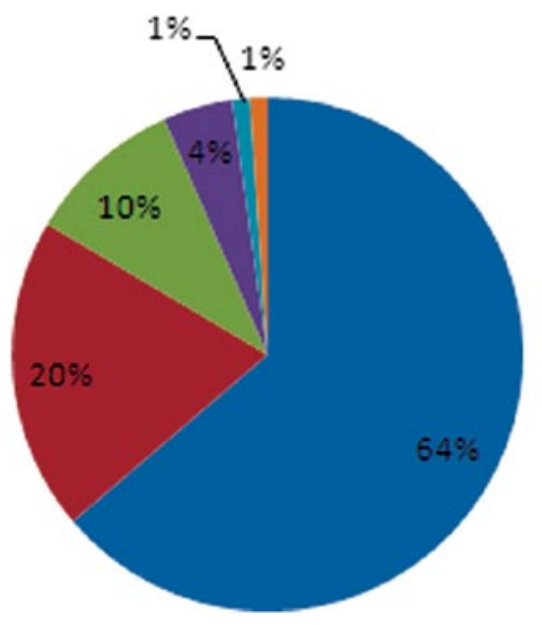

- Undergraduate

- Postgraduate (Taught)

n Postgraduate (Research)

- Academic Staff

SupportStaff

Member of the Public

Fig. 7: Percentage distribution of school responses to online survey.
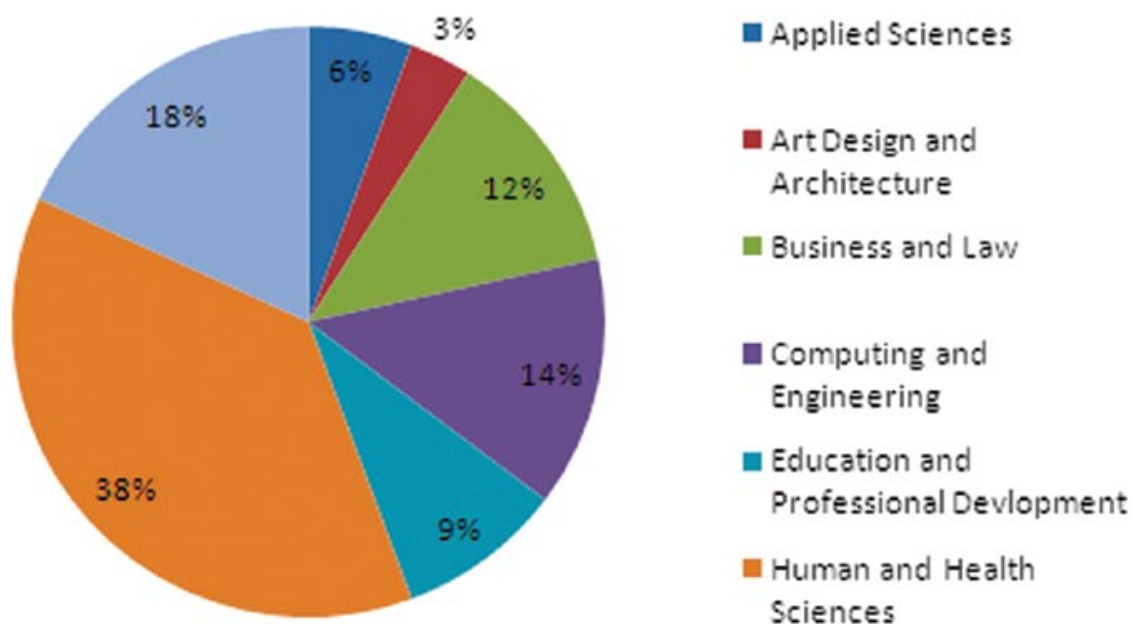

help was needed, 'only because I wasn't sure what databases I was searching in, but after completing a search I realised it showed anything relevant'. The confusion over Summon vs. traditional databases was indentified at an early stage and continues to be an issue. 
$44 \%$ of users refined their searches, mostly by using the facet options on the left of the screen. The comments imply that those that did, find it an easy process, although this may be linked to the way the first publicity flyers advertised the use of Summon. One user commented that they used ' + ' and '-' as they did on Google, while others used Boolean operators to refine the search.

Although $89 \%$ of replies stated the layout of results were clear, citing the facets and the ability to mouseover the title to view the abstract as particularly useful, a number of comments were received on the difficulty of accessing the full text even though the icon identifying the link to full text was showing. This was due to teething troubles with the links via the Serials Solutions knowledge base and not down to any issues with Summon itself and was rectified early on in the beta phase.

Relevance of search results featured highly on the Huddersfield specification list and $84 \%$ of users agreed that results were relevant to their research topic. $77 \%$ said they found what they were looking for. $73 \%$ found the advanced search easy to use and $80 \%$ thought that there were enough features offered.

Users were asked what they most liked and disliked about Summon. 'Ease of use' and 'simplicity' ranked highly as the best features. One user found Summon 'incredibly simple to use, seems much faster to access journals/articles', while another liked 'the fact that it brings all the different parts of the library into a Google-like search option'. The majority of negative comments related to the issues surrounding access to full text or that there was nothing they didn't like. However, one commented that 'it's still not a Google box', while another disliked it because of 'its Google-like operationality'. Some comments were also received about the order of results and about the fact that Summon did not list the results on the initial screen by type, e.g. article, book etc. Overall, the results were positive and backed up many of the alterations that were made prior to the beta launch.

\section{Focus Groups}

The Summon Implementation Group liaised with colleagues at Northumbria University regarding ideas for focus groups with a view to holding similar sessions in order to be able to benchmark results as part of the JISC project. 
Focus groups will take the form of an hour-long session with 10 minutes given to a welcome, introduction and explanation of the format of the session. 20 minutes are provided for focus group members to perform a number of pre-prepared searches while library staff observe them. Finally, 30 minutes are set aside for group discussion using a set of open questions adapted from the initial questionnaire and those used by Dartmouth College Library (Dartmouth, 2009, p. 30-32). Early indications from the focus groups held so far are that ease of use features highly on students comments.

\section{Further Evaluation}

At the time of writing, it is also intended to use screen capture software to track what the users are doing when searching Summon. This will either be used as part of the focus groups sessions or at a later date with a different cohort. User training will also feature highly in getting specific comments from users. Analysis of results of all user evaluation from both Huddersfield and Northumbria will be published at a later date.

\section{Training and Awareness}

As part of the countdown to the full launch of Summon at the end of July, the Implementation Group has undertaken a series of training sessions for both Library staff and users.

\section{Staff Training}

Full training in the use of Summon across the whole service is to take place in three steps. At the beta launch it was realised that because of the membership of the Implementation Group, not all members of the Library Enquiry Desk Team, consisting mostly of subject librarians, considered themselves experts in searching Summon. Although several staff briefings had taken place since early January, not all subject librarians felt confident. This was considered a major issue for a number of reasons. Firstly because the 'Ask a Librarian Desk' was to market the beta launch from the outset, offering Summon as an alternative to the current system, but also because user training was to be conducted by the subject librarians. Therefore a session with 
these staff was held to help them grasp the concept of Summon before they went away to update their training material.

Following this, a series of in-depth training sessions were to be held throughout June/July. All Library staff have been asked to sign up to a session. These will take the form of part presentation, part hands-on session with scenarios to work through in an IT lab. These sessions are designed to give all library staff a basic introduction to Summon, to prepare them to be able to recommend the service to library users and to troubleshoot enquiries.

Finally a short series of refresher sessions are planned for September. These general awareness sessions are to remind staff of the new service after the summer break in readiness for the new academic year.

\section{User Training}

One of the benefits of launching a new service in July is that once the new academic year starts in September, up to one third of users will not know any other system. In order to help the continuing students adapt to the new service eight lunchtime drop-in sessions were advertised. These sessions worked through the existing publicity in addition to a number of worked examples that staff had prepared as a result of the library staff sessions. Given that these sessions were taking place during the beta period, the sessions were themselves viewed as a learning experience for library staff as much as they were for the users.

In advance of these sessions, subject librarians were encouraged to sign up to the staff-only Summon blog, designed to help them keep abreast of any new developments, whilst encouraging them to comment on any issues raised.

The suggested format of the sessions was to market Summon as the new discovery tool for the coming academic year and a number of key messages were relayed:

- Get ahead for next year by previewing Summon

- Summon is as easy to use as Google Scholar, but better in that full text can be linked to straightaway 
- Summon is topic-based rather than resource-based

- There a 3 steps: search, review results, view abstract/full text

- Keywords are crucial

- A-Z lists are still available

- Feedback is important

At the time of writing, feedback from the sessions run so far has been extremely positive from the students. Academic staff have been more reserved and have been quite apprehensive of the change. However, many have appeared happier when shown Summon.

One-to-one sessions are also being offered to researchers and academic staff and the 'Summon explained' leaflet was provided to allay any fears over the move to the new service. In addition it is planned to produce an electronic resource pack for staff featuring approved logos, screen dumps etc. for inclusion in course packs, module handouts and the VLE. When finalised, this material will also be available via the ISC project blog.

Informal feedback from the user training sessions will inform future training sessions and will also highlight key areas to take to Serials Solutions for future product development.

\section{Future Product Development}

In order for Summon to remain relevant and to keep ahead of its competitors it must continue to develop as a product. The same applies to the systems and services provided to users of the University of Huddersfield. Feedback provided by users and library staff at Huddersfield throughout the beta test and through informal comments from the widening Summon user group has highlighted a number of areas for future development.

Statistics. Summon does not currently have a usage statistics module. It is imperative that, if Summon is to mature as a product, this module is developed, otherwise libraries will only have circumstantial evidence to show whether Summon is providing value for money, e.g. decreases in database searching, link resolver click-throughs and increases in full text resources and feedback from users (Way, 2010). Recent discussion on the Summon users listserv has provided a list of statistical reports that are needed by users, such 
as user information, search results, saved items and special requests including Google Analytics integration. However, the top priority must surely be for COUNTER compliance, this would enable Summon to be benchmarked against other resources. Ideally Database Report 1 compliance should be provided.

University Archives. Summon gives the University Library the potential to provide resource discovery to its whole collection. The archive collection is a good example of a collection that has not been exploited to its full potential. Although without significant investment it will not be possible to add every item in the archive, it will be feasible to add collection-based records. The benefits of this will be twofold. Not only will Huddersfield users of Summon be able to see the archive collections, but by making the data available to all Summon customers, potential external users will be able to view the collections.

Personalisation. Although Summon ticked the boxes during the evaluation process, one area that did not score highly was personalisation. One vision discussed early on in the evaluation process was that personalisation could be used, for example, a psychology student searching for organisational behaviour would see a different set of results to students studying business, education or health. This could be achieved through knowing who that student was and weighting the results accordingly.

However, any personalisation such as this is in direct contradiction to an open, searchable Google-like interface such as Summon. Having said this, Google does manage to do both, so therefore it is certainly a viable aspiration for libraries to expect Summon to give both easy, fast and relevant searches, plus a degree of personalisation if users are prepared to log on to 'My Summon'.

Saving items. Another potential area for personalisation is the saving of results. At present any saved results are lost when a session is terminated unless specifically imported in Zotero, Endnote or similar bibliographic software. Initial responses from subject librarians indicate that the ability to save searches and results within Summon is highly desirable for users, simply because they are used to this with others electronic resources.

Library Catalogue. To take the idea of personalisation further from a library systems point of view, it should be feasible to remove all electronic resources 
from the library catalogue in favour of marketing Summon as the search for all library content and the catalogue as a search of print content within the building. This is far easier now that all print and electronic records have been split in order for Summon to display record details in the facets correctly.

To take this one stage further, it would seem sensible to replace the library catalogue interface with a personalised version of the Summon interface that would only search the 'print collection'. The benefit to users would be that only one interface was used for Summon and the library catalogue.

The main issue with this approach at the moment is the question over what to do with the patron functions such as renewals, reservation etc.

Availability of new resources in Summon. Serials Solutions are to be congratulated on the success of acquiring new content for Summon. However, there is often a significant delay between acquiring the content and making it available in the knowledge base. Whilst this is entirely justified giving the sheer amount of content, there is a lack of communication at this point. It is suggested that as part of any admin module that would include usage statistics etc., Serials Solutions add a list of the new resources together with the planned date that the data will become available and any slippage expected, in a similar vein to the information shown as part of the Database Title List Updates section of the IISC Academic Database Assessment Tool (ADAT). This degree of openness will help customers manage user expectation.

Updates of existing material. Some concern has been expressed regarding the availability of current journal issues. It is essential that new journal content is added as quickly as possible, and if there is any significant delay, customers need to be advised as soon as possible. The potential lack of current material is seen as a major risk. Users are now familiar with getting new content immediately on publication; if they perceive this as an issue they will soon move away from Summon.

\section{Looking Forward}

From the very start of the project, it was clear that the implementation of Summon would radically change the way information literacy sessions 
were taught. Although it is still early days, it looks like it will take some time to move users from choosing a database to search to using Summon as a one-stop-shop. The very nature of the ways users search will be turned on its head, from searching databases that include all content and then hoping that the abstracts chosen will hold the full text, to searching the full-text subscribed material first and then widening the search if necessary. Over time subject teams will no longer have to concentrate their efforts on showing users the correct databases to search. Rather, they can teach users the correct way to search, a return to information literacy sessions. The subject teams are already addressing this in the new guides and handbooks that are being written in consultation with users in the beta period; it is also hoped that the simplicity of Summon will address the issue of low/non-use of library resources reported by White and Stone (White and Stone, 2010), where the analysis of e-resource usage, book loans and gate entry figures in groups exhibiting low/non-usage behaviour has been linked to student attainment.

The University of Huddersfield is now nearly one year into a three-year deal with Serials Solutions for Summon. On reflection, we are happy with the time it has taken between signing and going live. The Summon Implementation Group has learnt a great deal and Summon is continuing to mature as a product. The next twelve months will be an exciting time for us as we roll out the new service to the whole University. Further analysis of the implementation and evaluation of user feedback and training will shortly be made available as part of the joint JISC project with Northumbria University. In 2012, towards the end of the Summon contract, we intend to review Summon to see if it continues to be a groundbreaking product and to assess its competitors in what could be a dramatically different marketplace.

\section{Acknowledgements}

The author would like to acknowledge the invaluable contribution of the Summon Implementation Group; Dave Pattern (responsible for all in-house customisation), Lisa Balman, Steve Carr, Deborah Goodall, Eileen Hiller (chair), Jane Kaye, Alison Sharman and Andrew Walsh; also Alan Radley, Chair of the original working group. 


\section{References}

Bell, S. (2005): 'Submit or Resist: Librarianship in the Age of Google', American Libraries, 36(9), 68-71.

Blenkle, M., R. Ellis and E. Haake (2009): 'Next generation library catalogues: review of E-LIB Bremen', Serials, 22(2), 178-181. DOI: 10.1629/22178.

Breeding, M. (2010): 'The state of the art in library discovery 2010', Computers in libraries, 2010, 30(1), 31-34.

CIBER (2007): Information behaviour of the researcher of the future ('Google Generation' Project), University College London, CIBER. http:/ /www.ucl.ac.uk/infostudies/ research/ciber/downloads/ggexecutive.pdf (accessed 11 June 2010).

Dartmouth College Library (2009): An evaluation of Serials Solutions Summon: as a discovery service for the Dartmouth College Library, Hanover, NH, Dartmouth College Library.

Duddy, C. (2009): A student perspective on accessing academic information in the Google era, 32nd UKSG Annual Conference and Exhibition, 30 March-1 April 2009, Riviera International Conference Centre, Torquay.

Duvernay, J. (2010): Promoting Library One Search at Arizona State University, The success of web-scale discovery in returning net-gen users to the library, Library journal webcast April 8, 2010. http://www.libraryjournal.com/lj/tools/webcast/883883-

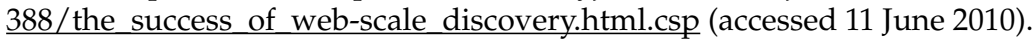

Gibson, I., L. Goddard and S. Gordon (2009): 'One box to search them all: implementing federated search at an academic library', Library Hi Tech, 27(1), 118-133. DOI 10.1108/07378830910942973.

King, D. (2008): 'Many libraries have gone to federated searching to win users back from Google. Is it working?', Journal of Electronic Resources Librarianship, 20(4), 213-227. DOI: 10.1080/19411260802554520.

Lampert, L.D. and K.S. Dabbour (2007): 'Librarian perspectives on teaching Metasearch and federated search technologies', Internet Reference Services Quarterly, 12(3/4), 253-278. DOI: 10.1300/J136v12n03_02.

Lauridsen, H. and G. Stone (2009): 'The 21st-century library: a whole new ball game?' Serials, 22(2), 141-145. DOI: 10.1629/22141.

Mayfield, I., L. Humphreys, S. Shadle and M. Watson (2008): 'Next generation library catalogues: reviews of ELIN, WorldCat Local and Aquabrowser', Serials, 21(3), 224-230. DOI: $10.1629 / 21224$.

Nicholas, D. (2008): 'If we do not understand our users, we will certainly fail', E-Resources Management Handbook, UKSG, Oxford. DOI: 10.1629/9552448_0_3.13.1. 
Nicholas, D., P. Huntington, H.R. Jamali, I. Rowlands and M. Fieldhouse (2009): 'Student digital information-seeking behaviour in context', Journal of Documentation, 65(1), 106-132. DOI: 10.1108/00220410910926149.

Nygren, E., G. Haya and W. Widmark (2006): Students experience of Metalib and Google Scholar, Stockholm, Universitetsbiblioteket.

Pattern, D. (2009): OPAC 2.0 and beyond. 32nd UKSG Annual Conference and Exhibition, 30 March-1 April 2009, Riviera International Conference Centre, Torquay. http://eprints.hud.ac.uk/4143/ (accessed 11 June 2010).

Research Information Network (2008): Ensuring a bright future for research libraries: a guide for vice-chancellors and senior institutional managers, London, RIN. http://www. rin.ac.uk/files/Ensuring bright future guide Nov08.pdf (accessed 11 June 2010).

Research Information Network (2009): Overcoming barriers: access to research information content, London, RIN. http:/ / www.rin.ac.uk/system/files/attachments/ Overcoming-barriers-report-Dec09 0.pdf (accessed 13 June 2010).

Serials Solutions (2009): 'University of Huddersfield is UK's First Commercial Adoption of the Summon Service', 25 August, http://www.serialssolutions.com/ news-detail/university-of-huddersfield-is-uks-first-commercial-adoption-of-thesummon-s/.

Shipp, J. (2009): University Librarian at the University of Sydney, comment at the Sydney Online conference January.

Stevenson, K., S. Elsegood, D. Seaman, C. Pawlek and M.P. Nielsen (2009): 'Next generation library catalogues: reviews of Encore, Primo, Summon and Summa', Serials, 22(1), 68-82. DOI: 10.1629/2268.

Stone, G. (2009): 'Resource Discovery', in: Digital Information: Order or anarchy? Facet, London, p. 133-164.

Tenopir, C. (2007): ‘Online databases: Can Johnny search?', Library Journal, 132(2), 30. http:/ / www.libraryjournal.com/article/CA6407784.html?industryid=47130 (accessed 11 June 2010).

Walker, J. (2009): 'Key issue: Mining information-seeking behaviour data to enhance library services', Serials, 22(2), 182-184. DOI: 10.1629/22182.

Walsh, A. (2010): Summon quick tutorial (Video) (Unpublished), http://eprints.hud. ac.uk/7509/

Way, D. (2010): Exploring the use of Summon at Grand Valley State University, The success of web-scale discovery in returning net-gen users to the library, Library journal webcast April 8, 2010. http://www.libraryjournal.com/li/tools/webcast/883883388/the success of web-scale discovery.html.csp (accessed 11 June 2010).

White, S. and G. Stone (2010): 'Maximising use of library resources at the University of Huddersfield', Serials, 23(2) (in press). 


\section{Websites Referred to in the Text}

COUNTER, http://www.projectcounter.org/

Educational Recordings Agency (ERA) licence, http://www.era.org.uk/

Electronic Resources Blog, http://library.hud.ac.uk/blogs/er/

Huddersfield Summon Page (Customised), http://library.hud.ac.uk/summon/

Huddersfield Summon Page (Default), http://hud.summon.serialssolutions.com/

Hudlib on Twitter, http://twitter.com/hudlib

JISC Academic Database Assessment Tool (ADAT), http://www.jisc-adat.com/adat/ home.pl

JISC Grant 12/09: Enhancing library management systems, http://www.jisc.ac.uk/ fundingopportunities/funding calls/2009/12/12091ms.aspxticTOCs Journal Tables of Contents Service, http://www.tictocs.ac.uk/

'Self-plagiarism is style'. Dave Pattern's blog, http://www.daveyp.com/blog/

Summon4HN project blog, http:/ / library.hud.ac.uk/blogs/summon4hn/

University of Huddersfield Repository, http://eprints.hud.ac.uk/

University of Huddersfield Research Festival, http://www2.hud.ac.uk/

researchfestival/events/central.php 